\title{
PERSPECTIVAS DE QUALIDADE DE VIDA DOS IDOSOS QUE TRABALHAM
}

\section{ARTIGO ORIGINAL}

ROCHA, Felipe Queiroz Dias¹, PICCIONE, Marcelo Arruda²

ROCHA, Felipe Queiroz Dias. PICCIONE, Marcelo Arruda. Perspectivas de qualidade de vida dos idosos que trabalham. Revista Científica Multidisciplinar Núcleo do Conhecimento. Ano 06, Ed. 11, Vol. 10, pp. 82-

100. Novembro de 2021. ISSN: 2448-0959, Link de acesso: https://www.nucleodoconhecimento.com.br/psicologia/perspectivas-de-qualidade, DOI: 10.32749/nucleodoconhecimento.com.br/psicologia/perspectivas-de-qualidade

\section{RESUMO}

O envelhecimento traz inúmeras consequências biopsicossociais no idoso e no relacionamento dele com outras pessoas. Dentro da Psicologia Social, o índice da satisfação é o principal indicador da experiência de um sujeito no diz respeito à sua qualidade de vida. $O$ interesse pela área da velhice aumentou, diante disto, o presente artigo, questiona sobre a qualidade de vida dos idosos que trabalham, realizando uma pesquisa com um grupo de idosos que trabalhadores. Objetivou-se observar a qualidade de vida dos idosos que trabalham segundo a sua perspectiva. Foram coligidos dados de 36 idosos com idade entre 65 e 87 anos, $\pm 5,4$, média 71,5 e mediana 71 que trabalham atualmente; para tanto, valeu-se de 36 questionários WHOQOL iguais. O teste não-paramétrico do Qui-quadrado foi aplicado para verificar se existe diferença estatisticamente significante. Dentre os resultados,

\footnotetext{
${ }^{1}$ Mestre em Ciências da Educação pela Faculdade de Psicologia e de Ciências da Educação da Universidade do Porto (FPCEUP); Mestre em Educação e Formação de Adultos pela FPCEUP; Psicólogo e Bacharel em Psicologia pela Universidade São Judas Tadeu (USJT).

${ }^{2}$ Especialista em Psicologia do Esporte e da Atividade Física pelo Instituto Sedes Sapientiae. Psicólogo e Bacharel em Psicologia pela Universidade São Judas Tadeu (USJT).
} 
destaca-se que $80,55 \%$ Concordam Totalmente com a premissa que sugere ficarem plenamente realizados quando estão em íntima comunhão com Deus; $72,22 \%$ dos voluntários Concordam Totalmente com a hipótese de estarem satisfeitos e realizados com suas vidas, $x_{0}{ }^{2}=15,54 \mathrm{e} \mathrm{x}^{2}{ }_{c}=7,81$, havendo diferença estatisticamente significante; $50 \%$ dizem que a vida tem Bastante sentido, $x_{0}{ }^{2}=8,30$ e $x^{2}{ }_{c}=9,48$, não havendo diferença estatisticamente significante; 47,22\% apontam ter um acesso Médio às informações diárias, $x_{0}^{2}=11,40$ e $x^{2}{ }_{c}=9,48$, havendo diferença estatisticamente significante; $41,66 \%$ classificam como Média as oportunidades de lazer que têm, $x_{0}{ }^{2}=4,41$ e $x^{2}{ }_{c}=9,48$, não havendo diferença estatisticamente significante; $38,88 \%$ Discordam Totalmente da premissa de que não encontram satisfação quando oram sozinhos, $x_{0}{ }^{2}=7,59$ e $x^{2}{ }_{c}=11,07$, não havendo diferença estatisticamente significante e $36,11 \%$ Concordam Totalmente com a hipótese de que sentem haver muitos conflitos e infelicidades na vida, $x_{0}{ }^{2}=6,09$ e $x^{2}{ }_{c}=11,07$, não havendo diferença estatisticamente significante. Percebeu-se que os idosos trabalhadores tendem a ter perspectivas distintas, mas mais propensas a respostas de cunho positivo, a respeito das diversas facetas investigadas de suas vidas, o que, por sua vez, denota seu grau de qualidade.

Palavras-chave: envelhecimento, biopsicossociais, satisfação, velhice.

\section{INTRODUÇÃO}

Qualidade de vida é um atributo multifacetado nos vários campos profissionais que a estudam. Dentro da Psicologia Social, o índice da satisfação é o principal indicador e maior referência do valimento da experiência de um sujeito. $O$ interesse pela área da velhice aumentou neste ínterim (TRENTINI; XAVIER e FLECK, 2006), diante disto, o presente artigo, questiona sobre a qualidade de vida dos idosos que trabalham, realizando uma pesquisa com um grupo de trabalhadores com idade igual ou superior a 65 anos.

Há três modos distintos em que um indivíduo pode atingir à terceira idade. A primeira é designada por velhice com patologia e é caracterizada pela presença de 
uma ou mais enfermidades que limitam demasiadamente os afazeres do sujeito, a ponto de as funções que este outrora cumpria se desvanecerem (TRENTINI; XAVIER e FLECK, 2006).

A segunda é a velhice usual ou normal e se trata do processo de envelhecimento acompanhado de disfunções físicas ou psíquicas em uma proporção amena, as quais ocasionam alterações fracionárias na vida comum dos idosos (TRENTINI; XAVIER e FLECK, 2006).

A terceira é a velhice bem-sucedida ou ótima e diz respeito ao processo com a manutenção da saúde plena como na época de apogeu do vigor, reproduzindo também uma condição satisfatória tangente ao bem-estar (TRENTINI; XAVIER e FLECK, 2006).

Dessa forma, compreende-se que envelhecer resulta em transformações biopsicossociais em cada indivíduo e, portanto, é incorreto compreender este fenômeno como uma patologia, pois se trata de um ciclo no qual o ser humano fica mais predisposto ao adoecimento. É uma época na qual as pessoas adoecem mais (ZIMERMAN, 2000).

O envelhecimento também transforma o status do idoso e o relacionamento dele com outras pessoas devido à: alteração de atribuições no âmbito familiar e social, encerramento da vida laboral, redução da interatividade interpessoal, questões financeiras e o risco de sofrer algum ato de violência (ZIMERMAN, 2000).

Após muito tempo de trabalho, o casamento é um fator valioso na construção do status social do sujeito. Quando ocorre a perda do consorte, o sênior sente solidão e tristeza e, ainda, fica sem previsões quanto ao futuro, o que gera sofrimento devido à ausência de comunicação significativa e de cuidado especial, além da eliminação da função social e do surgimento de sentimentos de imprestabilidade e falta de propósito na vida (SIMKUNAS e ANJOS, 2001). 
Para se livrar da solidão, a alternativa que recorrem é a busca por práticas coletivas, como atividades de cunho físico, como uma forma de se manter em ação afastandose do estado solitário (SIMKUNAS e ANJOS, 2001).

Com o maior acesso à informação e à participação, o idoso vem tendo oportunidades nos mais diversos âmbitos, inclusive no contexto do lazer, de expressar sua existência, sua aprendizagem, sua importância como cidadão detentor de direitos e garantias legais, seu envelhecimento e os níveis de sua efetiva contribuição dentro da sociedade (DE GÁSPARI e SCHWARTZ, 2005).

Assim, os estereótipos de inércia, sedentarismo, acomodação, tristeza, indisposição, fadiga, dores constantes, isolamento, depressão e falta de perspectivas ao longo desta etapa da vida vão desvanecendo gradativamente para a progressiva participação e adesão às inúmeras oportunidades que são oferecidas ao sujeito idoso nos diversos espaços da sociedade. Este fato vem chamando a atenção porque em cada local de frequência ou convivência social pode-se observar a presença do sênior cada vez mais consciente de sua capacidade de alterar o atual quadro de exclusão social que o estigmatiza para a condição de cidadão de segunda categoria e modificar os níveis de sua qualidade de vida (DE GÁSPARI e SCHWARTZ, 2005).

As experiências emocionais significativas no âmbito do lazer contemplam uma série de necessidades humanas radicais que podem corroborar o processo de desenvolvimento ao longo de todo o período vital, bem como para a elevação dos patamares qualitativos de vida da população, especialmente da concentrada nos centros urbanos da sociedade contemporânea (DE GÁSPARI e SCHWARTZ, 2005).

Porém, a pesquisa de Colalto (2002) indica que apenas $25 \%$ dos idosos têm muita oportunidade de lazer, $50 \%$ têm mediana oportunidade, $20 \%$ muito pouco e somente $5 \%$ têm completamente tal oportunidade. 0 mesmo autor ainda diz que somente $40 \%$ dos idosos estão satisfeitos com o serviço de saúde que possuem. 
Outro aspecto de grande peso nesse período é a religiosidade. O que se verifica é que professar uma fé facilita ao sênior ultrapassar esse último estádio da vida (ARAÚJO, 1999).

Assim, a religiosidade pode ser reputada como uma faceta propicia ao bem-estar na velhice, já que a coadjuvação em atividades construtivas e a presença de locais de boa estimulação, associada com as crenças, têm sido precípuos neste período. A espiritualidade pode estar relacionada a uma mais alta resiliência na senioridade (MARGACA e RODRIGUES, 2019).

Em outras palavras, a coparticipação em trabalhos religiosos, assim como a adesão a doutrinas e dogmas, pode estar conexa à felicidade por induzir significativamente na composição que o sênior cria sobre o mundo, entre bom ou mau. Assim, a religião pode deslindar a finalidade da vida e viabilizar o bem-estar (PANZINI et al., 2007).

A religião é um atributo que molda o indivíduo por meio de uma fé particular, que simboliza o encontro pessoal com a entidade divina (DINIZ, 2003).

Os atos (ritos) e os ditos (mitos) são basilares em todas as seitas e religiões, e são eles, portanto, os elementos que corroboram a produção de símbolos do que é sacro em nós. Assim, a religião pode ser definida como o atributo constatador das realidades vitais que a consciência é incapaz de assimilar, a qual provoca a sensação de unidade e inteireza humana plena quando alcança o estado de fruição psicológica integral (BAPTISTA, 2003).

Há indistinção entre os diversos estilos de vida levados pelos seniores no que tange a deprecação espiritual. A maior parte deles realiza preces pela obtenção de amor, saúde ou paz, por dilemas no seio familiar, para agradecer à divindade, entre outras causas (ORLANDO et al., 2008).

Assim, 15,53\% dos idosos dizem estar insatisfeitos com a vida. Este fenômeno está associado àqueles que são do sexo feminino, são analfabetos, têm até quatro anos 
de estudo e possuem renda inferior a dois salários mínimos. No entanto, essa prevalência é considerada baixa, apesar de evidenciar a necessidade de ações em favor da igualdade de gênero e de acesso dos seniores à educação (REINERS et al., 2020).

Nos casos de idosos que vivem em arranjos domiciliares multigeracionais, os que vivem em arranjos uni ou bigeracionais demonstraram maior satisfação com a vida do que os que habitam em trigeracionais, que, por sua vez, estão associados ao sexo feminino, viuvez e mais filhos (OLIVEIRA et al., 2020).

$\mathrm{Na}$ verdade, a sensação de significado positivo, de haver de um verdadeiro propósito na vida (o qual é subjetivo) e de tranquilidade com relação ao futuro aumenta e transcende $o$ dos jovens na medida em que os sujeitos vivem e amadurecem (FREITAS, 2020).

O propósito e a apreciação da vida são quesitos que favorecem o bem-estar e elevam em um terço a emissão de ações e sentimentos relativos à: autoaceitação, relações sociais saudáveis, progressão pessoal, controle do meio e objetivo, apesar de incrementarem pouquíssimo à satisfação com a vida e a emersão de emoções assertivas, assim como também reduzem muito pouco a emancipação de emoções contraproducentes, diferente da tranquilidade sobre o porvir, a qual favorece o bemestar e ainda aumenta significativamente os agentes emocionais assertivos e de satisfação com a vida, ao passo que as emoções contraproducentes são minimizadas na presença dessa serenidade (FREITAS, 2020).

Aqueles que situam uma razão para suas vidas têm habilidades sociais mais bem desenvolvidas e estão mais aptos para discernir e recorrer ao suporte necessário quando preciso - o bem-estar ou felicidade provém do objetivo existencial dado à vida. Essa razão é responsável por influenciar ligeira e positivamente no melhoramento psicológico e na forma como os sujeitos enfrentam seus desafios. É válido que as pessoas expectem um futuro auspicioso no afã de estarem motivadas 
perante os percalços típicos da vida e de decrescer os índices de ansiedade e de outros sintomas relativos ao que poderá vir (FREITAS, 2020).

Nesse ínterim, vê-se o valimento de haver sujeitos amadurecidos nas empresas, como seniores, os quais podem colaborar com o progresso, com o equilíbrio emocional e com o encontro da resposta mais adequada frente às necessidades organizacionais (FREITAS, 2020).

Assim, diversas indagações são suscitadas sobre como o envelhecimento será reputado pelas sociedades no futuro (VELOZ; NASCIMENTO-SCHULZE e CAMARGO, 1999).

No entanto, estabeleceu-se por objetivo geral investigar qual a perspectiva que os próprios idosos que trabalham têm sobre sua qualidade de vida em alguns âmbitos.

Mais especificamente, buscou-se:

- Averiguar como os idosos trabalhadores estão ao continuarem exercendo práticas laborais;

- Oferecer aos idosos que trabalham a chance de expressar suas perspectivas sobre o estado de alguns aspectos de suas vidas;

- Analisar com criticidade a situação geral da vida dos idosos que trabalham conforme as suas próprias perspectivas.

\section{METODOLOGIA}

\section{PARTICIPANTES}

Os dados foram coligidos de 36 indivíduos de ambos os sexos (sendo $88,90 \%$ homens e 11,10\% mulheres) com 65 anos de idade ou mais (que é a idade oficial para a cessação de atividades laborais, de acordo com a OMS) e que trabalhassem presentemente. A idade média obtida é de 71,5 anos, a amplitude de idade é de 22 anos, a mediana é de 71 anos e o desvio padrão é de 5,4. 


\section{MATERIAIS}

Valeu-se de 36 questionários WHOQOL exatamente iguais para se aferir a qualidade de vida dos seniores, uma vez que este material é internacionalmente reconhecido como uma ferramenta propicia para o alcance dos objetivos supracitados.

O referido questionário dispunha de três fases: a primeira se tratava de uma breve caracterização do participante; na segunda fase havia questões fechadas sobre diversos aspectos que envolvem a vida dos idosos, as quais deveriam ser respondidas mediante o nível de apreciação daquela questão colocada; a última parte continha proposições afirmativas e negativas que nivelavam a perspectiva do voluntário quanto àquela mesma proposição.

\section{PROCEDIMENTOS}

Os dados foram coligidos de uma amostra acidental nos meses de janeiro e fevereiro, ou seja, os idosos que estavam nas condições já mencionadas foram entrevistados pessoalmente sendo abordados em qualquer circunstância viável quando encontrados ocasionalmente. Todos os voluntários foram encontrados na cidade de São Paulo, de modo que 15 estavam na Mooca, seis no Brás, outros seis na Sé, cinco na Zona Cerealista, três na Vila Mariana e um no Cambuci.

De início, nos apresentávamos e expúnhamos o intuito da pesquisa. Depois, se a pessoa abordada se enquadrasse no perfil definido para os objetivos definidos e anuísse em participar, Ihe passávamos o Termo de Consentimento Livre e Esclarecido (TCLE) e o questionário a ser preenchido, além de, também, Ihe tirarmos qualquer dúvida eventual.

Este projeto foi submetido e aprovado no Comitê de Ética e Pesquisa (CEP) no 017/2005 e na CAAE 005.0.237.000.05. 


\section{RESULTADOS E DISCUSSÃO}

Os resultados obtidos através da coleta de dados com o material utilizado (WHOQOL) foram tabelados e serão apresentados e discutidos a seguir com base na literatura consultada e se relacionando entre si.

Tabela 1 - Medida em que a vida tem sentido

\begin{tabular}{|l|l|l|}
\hline Medida & F & $\%$ \\
\hline Nada & 1 & 2,77 \\
\hline Muito pouco & 3 & 8,33 \\
\hline $\begin{array}{l}\text { Mais ou } \\
\text { menos }\end{array}$ & 9 & 25 \\
\hline Bastante & 18 & 50 \\
\hline Extremamente & 5 & 13,88 \\
\hline Total & $\mathbf{3 6}$ & $\mathbf{1 0 0}$ \\
\hline
\end{tabular}

Fonte: autor.

Constata-se, na Tabela 1, que as variáveis mais votadas pelos participantes foram as alternativas Bastante e Mais ou menos, com $50 \%$ e $25 \%$, respectivamente. Ainda com relação à medida do sentido da vida, $13,88 \%$ dos participantes escolheram a opção Extremamente, 8,33\% optaram por Muito pouco e 2,77\% por Nada.

Com a intenção de verificar se há diferença estatisticamente significante, aplicou-se o teste não-paramétrico do Qui-quadrado. Obteve-se $x_{0}^{2}=8,30$ e $x^{2}{ }_{c}=9,48$, não havendo diferença estatisticamente significante. É válido salientar que n.g.l.=4 e $\alpha=0,05$.

$\mathrm{Na}$ Tabela 1 fica evidente que a maioria das respostas diz respeito à avaliação positiva. Com relação a isso, entende-se que o sentido da vida está relacionado diretamente a uma série de características relativas a várias tabelas apresentadas 
ao longo deste trabalho, que dizem respeito ao lazer, aos sentimentos diários, a realização pessoal, a religiosidade, entre outros.

Com respeito à família, estudos realizados por Simkunas e Anjos (2001), indicam que muito tempo de trabalho, o casamento é um fator valioso para construção do status social e na perda de um desse fator, o sujeito se sente sozinho, sem expectativas futuras, de modo a sofrer pela ausência de comunicação apreciável e de cuidado especial, até por perder sua função social, e assim fica exposto a sentimentos de imprestabilidade e falta de propósito na vida. Porém, informações mais pormenorizadas sobre esta faceta não foram coletadas entre os participantes.

Por outro lado, segundo Panzini et al. (2007), a religião é um quesito que pode deslindar a finalidade da vida e viabilizar o bem-estar. Podemos notar nas Tabelas 4 e 7 que os participantes se mostram bastante receptivos a esta faceta, visto que na primeira tabela citada $63,87 \%$ discordam em algum grau de ter insatisfação quando rezam sozinhos e, na segunda, $80,33 \%$ Concordar Totalmente que tem plena satisfação na íntima comunhão com Deus, o que configura um consenso entre essas premissas.

Deste modo, o sentido atribuído à vida do idoso deve passar pelo crivo da sua religião. Nas palavras de Margaca e Rodrigues (2019), a religiosidade é reputada como um elemento propício ao bem-estar na velhice, pelo que as convicções aderidas têm se mostrado precípuos neste período. A espiritualidade, ainda, pode estar relacionada a uma mais alta resiliência na senioridade. Araújo (1999) corrobora ao dizer que a professar uma fé facilita ao idoso a ultrapassagem desse último estádio da vida.

No mais, Freitas (2020) diz que a sensação de significado positivo, de existir um verdadeiro propósito (subjetivo) na vida e de haver tranquilidade com relação ao futuro aumenta ao longo da vida e do amadurecimento e transcende o dos indivíduos jovens. 
Freitas (2020) ainda diz que o sentido e a apreciação da vida são substratos influentes no bem-estar e elevam em um terço a emissão de ações e sentimentos relativos à: autoaceitação, relações sociais saudáveis, progressão pessoal, controle do meio e objetivo, apesar de incrementarem pouquíssimo à satisfação com a vida, ao contrário da tranquilidade sobre o porvir, a qual influencia o bem-estar e ainda aumenta significativamente os fatores emocionais assertivos e de satisfação com a vida, além de reduzir as emoções contraproducentes.

Freitas (2020) conclui dizendo que aqueles que encontram uma razão para suas vidas têm habilidades sociais melhor desenvolvidas e estão mais aptos para discernir e recorrer o suporte necessário quando preciso, já que o bem-estar ou felicidade provém do objetivo existencial dado à vida. Essa razão é responsável por influenciar ligeira e positivamente no melhoramento psicológico e na forma como os sujeitos enfrentam seus desafios.

Tabela 2 - Disponibilidade das informações diárias

\begin{tabular}{|l|l|l|}
\hline Disponibilidade & F & $\%$ \\
\hline Nada & 2 & 5,55 \\
\hline Muito pouco & 6 & 16,66 \\
\hline Médio & 17 & 47,22 \\
\hline Muito & 5 & 13,88 \\
\hline Completamente & 6 & 16,66 \\
\hline Total & $\mathbf{3 6}$ & $\mathbf{1 0 0}$ \\
\hline
\end{tabular}

Fonte: autor.

Percebe-se, na Tabela 2, que quanto à disponibilidade para as informações diárias, 47,22\% dos idosos classificam como Médio o seu acesso a tal, 16,66\% afirmam ser Muito pouco e outros $16,66 \%$ afirmam ser Completamente, além de 13,88\% que avaliam como Muito. Somente 5,55\% pela alternativa Nada. 
Para se descobrir se existe diferença estatisticamente significante aplicou-se o teste do Qui-quadrado. Obteve-se $x_{0}^{2}=11,40$ e $x^{2}{ }_{c}=9,48$, havendo diferença estatisticamente significante. Também é considerável que n.g.l. $=4$ e $\alpha=0,05$.

Com relação à tabela, as opiniões se dividem e são bem equilibradas no que diz respeito à disponibilidade das informações diárias, apesar de ligeira prevalência de acesso às mesmas.

Zimerman (2000) diz que o processo de envelhecimento transforma o status do idoso e o relacionamento dele com outras pessoas devido à: alteração de atribuições no seio familiar e social, encerramento da vida laboral, redução da interatividade interpessoal, questões financeiras e o risco de sofrer algum ato de violência nas ruas. A ocorrência dessas transformações requer a obtenção de informações para ser efetuadas. O que se pode indagar é: de onde vêm (ou deveria vir) essas informações: de sua busca autônoma, do apoio de familiares ou de outro lado? É impreciso saber se os participantes voluntários recebem ou esperam receber suporte nesse quesito por possivelmente terem dificuldades de usar meios de comunicação mais modernos, como computadores, para a obtenção de informações gerais acerca de suas mais variadas necessidades ou se conseguem fazer isto por si mesmos.

Ainda, fica necessário discutir também a possibilidade desta temática ser generalista e não incluir aspectos mais específicos quanto às opiniões e análise individual dos entrevistados. Dessa forma, seria interessante detalhar estas informações como sendo relacionadas a ações tanto da vida, de maneira geral, quanto no desempenho de funções, inclusive profissionais, e quanto às questões relativas à saúde e oportunidades de lazer ou educação.

Entretanto, De Gáspari e Schwartz (2005) pressupõem haver maior acesso à informação aos idosos, de modo a possibilitá-los a participar de oportunidades de atividades nos mais diversos âmbitos, o que desconstrói os estereótipos de inércia, sedentarismo, acomodação, tristeza, indisposição, fadiga, dores constantes, 
isolamento, depressão e falta de perspectivas em detrimento da progressiva participação e adesão às inúmeras oportunidades que são oferecidas ao sujeito idoso nos mais variados espaços da sociedade.

Tabela 3 - Oportunidades de lazer

\begin{tabular}{|l|l|l|}
\hline Oportunidade & F & $\%$ \\
\hline Nada & 7 & 19,44 \\
\hline Muito pouco & 7 & 19,44 \\
\hline Médio & 15 & 41,66 \\
\hline Muito & 4 & 11,11 \\
\hline Completamente & 3 & 8,33 \\
\hline Total & $\mathbf{3 6}$ & $\mathbf{1 0 0}$ \\
\hline
\end{tabular}

Fonte: autor.

Nota-se na Tabela 3 que a maioria $(41,66 \%)$ dos idosos entrevistados avalia como Médio o acesso ao lazer. Dessa forma, 19,44\% optaram pela alternativa Muito pouco, assim como Nada (outros 19,44\%). Por outro lado, $11,11 \%$ e $8,33 \%$ escolheram as opções Muito e Completamente, respectivamente.

O teste não paramétrico do Qui-quadrado foi utilizado para saber se há diferença estatisticamente significante; obteve-se $x_{0}^{2}=4,41$ e $x^{2}{ }_{c}=9,48$, não havendo diferença estatisticamente significante. Ressalta-se ainda que n.g.l. $=4$ e $\alpha=0,05$.

Com relação a este contexto, fica claro certo equilíbrio entre as opiniões dos entrevistados, mas também fica evidente certa insatisfação a respeito de poucas oportunidades de lazer. É possível que essa escassez de momentos de lazer esteja relacionada com as atividades de trabalho, as quais demandam tempo, mas essa informação pormenorizada não pôde ser investigada pelo questionário.

Seja como for, De Gáspari e Schwartz (2005) dizem que com o maior acesso à informação e à participação social do idoso, os mesmos vêm tendo oportunidades 
no contexto do lazer de expressar sua existência, sua aprendizagem, sua importância como cidadão detentor de direitos e garantias legais, seu envelhecimento e os níveis de sua efetiva contribuição dentro da sociedade.

Isto, inclusive, de acordo com De Gáspari e Schwartz (2005), desconstrói gradualmente os estereótipos de inércia, sedentarismo, acomodação, tristeza, indisposição, fadiga, dores constantes, isolamento, depressão e falta de perspectivas ao longo desta etapa da vida para a progressiva participação e adesão às inúmeras oportunidades disponíveis ao idoso nos mais variados espaços sociais.

Em sua pesquisa, Simkunas e Anjos (2001) relatam que todos os sujeitos entrevistados citam que a participação em práticas coletivas, como atividades de foro físico, são formas de se manter lépidos e os afastam do estado de solidão.

As experiências emocionais significativas no microcosmo do lazer contemplam uma série de necessidades humanas que podem corroborar o processo de desenvolvimento ao longo de todo o período vital, bem como para a elevação dos níveis qualitativos de vida da população, especialmente da concentrada nos centros urbanos da sociedade atual, segundo De Gáspari e Schwartz (2005).

Por sua vez, Colalto (2002) diz que apenas $25 \%$ dos idosos têm muita oportunidade de lazer, $50 \%$ têm mediana oportunidade, $20 \%$ muito pouco e somente $5 \%$ têm completamente. Esses dados são semelhantes aos da Tabela 3, com ressalva para a variável Muito, a qual detém $11,11 \%$ das respostas na referida tabela e $25 \%$ no trabalho citado.

Dentro desse quadro, o questionamento de Veloz; Nascimento-Schulze e Camargo (1999) sobre como a velhice será vista no futuro tem pertinência, visto que o trabalho pode assumir a condição de ocupação do tempo ocioso do sujeito sênior nesse estágio apesar do suposto acesso a esse tipo de atividade citado por De Gáspari e Schwartz (2005). 
Tabela 4 - Insatisfação quando se reza/ora sozinho

\begin{tabular}{|l|l|l|}
\hline $\begin{array}{l}\text { Grau de satisfação } \\
\text { Concordo Totalmente }\end{array}$ & 5 & $\%$ \\
\hline $\begin{array}{l}\text { Concordo Parcialmente } \\
\text { Concordo mais que } \\
\text { discordo }\end{array}$ & 5 & 13,88 \\
\hline $\begin{array}{l}\text { Discordo mais que } \\
\text { concordo }\end{array}$ & 3 & 8,33 \\
\hline $\begin{array}{l}\text { Discordo Parcialmente } \\
\text { Discordo Totalmente }\end{array}$ & 6 & 16,66 \\
\hline $\begin{array}{l}\text { Total mal } \\
\text { Dism }\end{array}$ & $\mathbf{3 6}$ & $\mathbf{1 0 0}$ \\
\hline
\end{tabular}

Fonte: autor.

Nota-se na Tabela 4 que a maior parte dos idosos que participaram da pesquisa disse que Discorda Totalmente (38,88\%) que não encontram muita satisfação quando rezam ou oram sozinhos, 16,66\% Discordam Parcialmente, 13,88\% Concordam Parcialmente, outros 13,88\% Concordam Totalmente, 8,33\% Concordam mais que discordam e outros 8,33\% Discordam mais que concordam.

Sabe-se ainda que $x_{0}^{2}=7,59$ e $x^{2}{ }_{c}=11,07$; uma vez que para verificar se há diferença de estatisticamente significante aplicou-se o teste não-paramétrico do Qui-quadrado; descobriu-se que tal diferença não existe. Salienta-se também que n.g.l.=5 e $\alpha=0,05$.

Baptista (2003) diz que os atos (ritos) e as ditos (mitos) são basilares em todas as religiões e são os elementos que corroboram a criação de símbolos do que é sacro em cada ser humano. Assim, considerando a prática de orações como um rito, Orlando et al. (2008) dizem que os idosos costumam pedir em suas preces por propósitos como bênção familiar, obtenção de paz e amor e por sua saúde, além de agradecerem pelos favores alcançados. 
Diniz (2003) fala que a religião é um atributo que molda o indivíduo através de uma fé particular, a qual significa um encontro com pessoal com a entidade divina cultuada; ou seja, trata-se de uma experiência individual.

Araújo (1999) diz que a causa para o bem-estar do idoso em praticar uma religião é por sentir-se ajudado a ultrapassar com mais facilidade esse último estádio da vida.

Deste modo, segundo Margaca e Rodrigues (2019) e Panzini et al. (2007), a religião pode ser considerada como uma faceta favorável ao bem-estar e a resiliência na velhice por influenciar o modo como sujeito interpreta o mundo.

Tabela 5 - Realização e satisfação com a vida

\begin{tabular}{|l|l|l|}
\hline Felicidade & F & $\%$ \\
\hline Concordo Totalmente & 26 & 72,22 \\
\hline \begin{tabular}{l|l|} 
Concordo Parcialmente \\
Concordo mais que \\
discordo
\end{tabular} & 7 & 19,44 \\
\hline $\begin{array}{l}\text { Discordo Totalmente } \\
\text { Total }\end{array}$ & 1 & 2,77 \\
\hline & 36 & $\mathbf{1 0 0}$ \\
\hline
\end{tabular}

Fonte: autor.

É possível observar na Tabela 5 que 72,22\% dos entrevistados optaram pela variável Concordo Totalmente no que diz respeito à realização e satisfação com a vida. Outros 19,44\% também Concordam Parcialmente; e 5,55\% Concordam mais que discordam. Somente $2,77 \%$ disseram que Discordam Totalmente. As demais variáveis, Discordo Parcialmente e Discordo mais que concordo, foram eliminadas por não terem sido apontadas por nenhum dos sujeitos.

Destaca-se ainda que $x_{0}^{2}=15,54$ e $x^{2} c=7,81$; uma vez que para verificar se há diferença estatisticamente significante o teste do Qui-quadrado foi aplicado; descobriu-se que há essa diferença. Considera-se ainda que n.g.I.=3 e $\alpha=0,05$. 
Esses resultados são compatíveis com os da Tabela 7, que mostra que 80,55\% Concordam Totalmente com a premissa que diz estarem em plena realização quando estão em íntima comunhão com Deus. Esta congruência denota que a religiosidade é uma faceta capaz de trazer realização e satisfação aos idosos, o que também está em consonância com o que dizem Araújo (1999), Margaca e Rodrigues (2019) e Panzini et al. (2007).

Reiners et al. (2020) dizem que $15,53 \%$ dos idosos estão insatisfeitos com a vida. As características demográficas prevalentes dos sujeitos que reportam tal insatisfação são o sexo feminino, o analfabetismo, ter até quatro anos de estudo e possuir uma renda mensal inferior a dois salários mínimos. Vale ressaltar que essa prevalência é considerada baixa.

Esses dados são totalmente antagônicos aos da Tabela 5, mas é fácil perceber o motivo dessa incompatibilidade: a demografia das amostragens é distinta, visto que os idosos trabalhadores são em sua maioria homens (88,90\%). Não se obteve informações mais pormenorizadas do rendimento e do grau de instrução dos participantes, mas é razoável supor que seja o suficiente para a sua satisfação profissional e econômica dada à prevalência de $97,23 \%$ de respostas que concordam com essa premissa. Considerando isso, os dados obtidos por Reiners et al. (2020) corroboram os da Tabela 5 e vice-versa, uma vez que as amostras contrastam entre si.

Freitas (2020) diz que a apreciação da vida é um quesito que influencia o bem-estar e eleva em um terço a emissão de ações e sentimentos relativos à: autoaceitação, relações sociais saudáveis, progresso pessoal, controle do meio e objetivo, apesar de incrementarem pouquíssimo à satisfação com a vida; diferente da tranquilidade sobre o porvir, a qual influencia o bem-estar e ainda aumenta significativamente os fatores emocionais assertivos e de satisfação com a vida, enquanto as emoções contraproducentes decrescem quando há essa serenidade e sentimentos. Vale frisar que Trentini; Xavier e Flack (2006) dizem que o grau de satisfação é o conceito mediador de qualidade de vida na Psicologia Social. 
Oliveira et al. (2020) finalizam dizendo que idosos que vivem em arranjos domiciliares uni ou bigeracionais demonstram maior satisfação com a vida do que os que habitam em trigeracionais, os quais, por sua vez, estão associados ao sexo feminino, viuvez e mais filhos. A amostragem dos insatisfeitos é compatível com a do trabalho de Reiners et al. (2020).

Tabela 6 - Sensação de que há muitos conflitos e infelicidades na vida

\begin{tabular}{|l|l|l|}
\hline Pessimismo & F & $\%$ \\
\hline $\begin{array}{l}\text { Concordo Totalmente } \\
\text { Concordo Parcialmente }\end{array}$ & 13 & 36,11 \\
\hline $\begin{array}{l}\text { Concordo mais que } \\
\text { discordo }\end{array}$ & 3 & 8,33 \\
\hline $\begin{array}{l}\text { Discordo mais que } \\
\text { concordo }\end{array}$ & 1 & 2,77 \\
\hline $\begin{array}{l}\text { Discordo Parcialmente } \\
\text { Discordo Totalmente }\end{array}$ & 3 & 8,33 \\
\hline Total & 5 & 13,88 \\
\hline
\end{tabular}

Fonte: autor.

Percebe-se na Tabela 6 que com respeito à sensação de que há muitos conflitos na vida, 36,11\% idosos Concordam Totalmente, 30,55\% Concordam Parcialmente e $13,88 \%$ Discordam Totalmente. Há dois grupos de $8,33 \%$ que Concordam mais que discordam e Discordam Parcialmente. Somente $2,77 \%$ Discordam mais que concordam.

Aplicou-se o teste do Qui-quadrado para averiguar se existe diferença de significância resultou-se dele $x_{0}{ }^{2}=6,09$ e $x^{2}{ }_{c}=11,07$. Também se frisa que n.g.l. $=5$ e $\alpha=0,05$.

Nota-se que $75 \%$ dos participantes voluntários concordam que há muitos conflitos na vida, essa informação atrita com as informações sobre questões religiosas 
obtidas nas Tabelas 4 e 7, já que os idosos se mostram satisfeitos e contentes, em sua maioria.

Esses resultados também são incongruentes com os da Tabela 5. Estes apontam que $72,22 \%$ dos idosos voluntários Concordam Totalmente com a premissa de que estão realizados e satisfeitos com suas vidas.

É válido citar as palavras de Panzini et al. (2007), os quais dizem que a religião pode deslindar a finalidade da vida, viabilizar o bem-estar e que a participação em atividades desse cunho pode estar relacionadas à felicidade.

Talvez esse contraste dê pelo fato de os idosos reconhecerem que inerentemente existem momentos de turbulência e dificuldade ao longa vida, apesar de considerarem-se realizados e satisfeitos. Todavia, esta hipótese não pôde ser investigada mais profundamente, assim como outras possíveis razões para esta contraposição.

Tabela 7 - Plena realização na íntima comunhão com Deus

\begin{tabular}{|c|c|c|c|c|}
\hline \multirow{2}{*}{\multicolumn{3}{|c|}{$\begin{array}{l}\text { Realização } \\
\text { Concordo Totalmente }\end{array}$}} & $\mathrm{F}$ & $\%$ \\
\hline & & & 29 & 80,55 \\
\hline \multicolumn{3}{|c|}{ Concordo Parcialmente } & 4 & 11,11 \\
\hline $\begin{array}{l}\text { Concordo } \\
\text { discordo }\end{array}$ & mais & que & 2 & 5,55 \\
\hline $\begin{array}{l}\text { Discordo } \\
\text { concordo }\end{array}$ & mais & que & 1 & 2,77 \\
\hline Total & & & 36 & 100 \\
\hline
\end{tabular}

Fonte: autor.

Vê-se na Tabela 7 que $80,55 \%$ dos sujeitos Concordam Totalmente com a afirmação de que possuem uma realização plena quando estão em íntima comunhão com Deus. Somente $11,11 \%$ Concordam Parcialmente e 5,55\% Concordam mais que 
discordam. A opção menos apontada foi Discordo mais que concordo, por 2,77\% dos entrevistados. As variáveis Discordo Parcialmente e Discordo Totalmente foram eliminadas por não terem sido citadas.

Ressalta-se que $x_{0}^{2}=0$ e $x^{2} c=7,81$; já que 0 teste do Qui-quadrado foi aplicado para descobrir se há diferença estatisticamente significante; verificou-se que não existe diferença estatisticamente significante. É válido frisar ainda que n.g.l.=3 e $\alpha=0,05$.

Esses resultados são semelhantes aos da Tabela 5, que mostra que $72,22 \%$ dos voluntários Concordam Totalmente com a premissa de estarem satisfeitos e realizados com a vida.

Embora com uma curiosa diferença de porcentagem entre as variáveis, nota-se que os resultados da Tabela 7 têm compatibilidade com os da Tabela 4, na qual percebe-se que 63,87\% dos participantes dizem discordar em algum grau da premissa de terem insatisfação quando rezam sozinhos. Apenas $38,88 \%$ dizem Discordar Totalmente (que é a opção que contrasta diretamente com a alternativa Concordo Totalmente, a mais na Tabela 7) de tal premissa.

As razões para isso podem ser a falta de compreensão da questão (a qual foi elaborada em forma de uma sentença negativa pelo questionário WHOQOL, o que, por sua vez, é incomum na linguagem popular cotidiana) no momento da coleta de dados ou pela comunhão com Deus poder estar associada com práticas distintas da oração.

Orlando et al. (2008) dizem que, independentemente do estilo de vida, os idosos rezam por vários propósitos, como obtenção de paz, obtenção de amor, gratidão por um favor alcançado e pela família. Todos estes pedidos estão ligados ao estado de espírito do ser humano, ainda que indiretamente (como o bem-estar de um familiar), de modo ser dúbio desconsiderar a prática de orações como um meio de comunhão com Deus. Deste modo, ou alguns participantes realmente não compreenderam a questão (possivelmente pelos motivos supracitados) ou há outra circunstância não observada que levou os idosos a optarem por uma maior diversidade de alternativas 
(talvez pela falta de aprofundamento disponibilizado pelo instrumento de coleta de dados utilizado), considerando que a questão da Tabela 7 estava menos ambígua por ser uma sentença afirmativa.

\section{CONCLUSÃO}

Respondendo à questão norteadora sobre a qualidade de vida dos idosos que trabalham, percebeu-se que os idosos trabalhadores possuem graus distintos de satisfação com os aspectos investigados que envolvem suas vidas, segundo sua própria perspectiva expressada no material utilizado. Porém, eles apresentam uma tendência maior de estarem satisfeitos do que insatisfeitos na maioria das facetas investigadas, já que demonstraram maior apreciação com algumas delas (como a religiosidade).

Essa amálgama de satisfação e insatisfação suscita questionamentos particulares em cada faceta observada, os quais não puderam ser investigados uma vez que não se trabalhou com um método de coleta de dados aberto ou semidirigido que pudesse aprofundar mais a análise de cada área. No entanto, foram abertas portas para que estas perguntas problemas possam alavancar novas pesquisas que continuem ou até completem este trabalho (por exemplo: A falta de informações diárias e de acesso ao lazer por parte dos idosos é decorrente de um processo de segregação praticado pela família ou decorrente das horas dedicadas ao trabalho?).

Deste modo, recomenda-se que novas pesquisas sejam realizadas para se investigar de forma mais profunda a qualidade de algumas facetas da vida dos idosos (especialmente as que ficaram ambíguas, indefinidas ou à margem de hipóteses), inclusive desvelando-se o grau de satisfação de alguns novos aspectos. O material utilizado foi preciso para o trabalho de dados quantitativamente, mas inflexível para a análise qualitativa, de modo a deixar pontas soltas na prospecção das informações tabeladas correlacionadas com a literatura consultada e entre si. Também se sugere que uma pesquisa de teor similar seja realizada com idosos que não trabalham para se comparar os resultados entre os que exercem tais atividades 
e os que já se encontram aposentados, pois pode ser possível haver diferenças significativas nas respostas em alguns âmbitos.

No mais, estima-se que esta contribuição científica possa corroborar para que haja questionamentos acerca da realidade vivida por muitos idosos que trabalham e investimentos na melhoria da sua qualidade de vida, especialmente nos aspectos abordados em que não houve prevalência de satisfação.

\section{REFERÊNCIAS BIBLIOGRÁFICAS}

ARAÚJO, C. D. S. F. Aspectos religiosos do idoso. In: PETROIANO, A.; PIMENTA L. G. Clínica e cirurgia geriátrica. Rio de Janeiro, Guanabara, p.8-9, 1999.

COLALTO, R. M. C. Qualidade de vida na terceira idade. In: Universidade Camilo Castelo Branco. Monografia como pré-requisito de Trabalho de Conclusão de Curso de graduação em Psicologia - p. 49. São Paulo, 2002.

DE GÁSPARI, Jossett Campagna; SCHWARTZ, Gisele Maria. O idoso e a ressignificação emocional do lazer. Psicologia: Teoria e Pesquisa. Araras, № 1 , v.21, p.69-76, 2005. Disponível em http://www.scielo.br/scielo. Acessado em 31 de maio. 2021. ISSN 1806-3446. https://doi.org/10.1590/S0102-37722005000100010.

DINIZ, L. Espiritualidade e Arte Terapia. In: Arte Terapia Coleção Imagens da Transformação. Revista POMAR. Rio de Janeiro, no 10, v.10, p.109-124, 2003.

FREITAS, Lucia Helena Walendy de. A influência do sentido da vida sobre o bem estar. Archives of Health. Curitiba, no 1, v.6, p.432-447, 2020. Disponível em https://latinamericanpublicacoes.com.br. Acessado em 9 de junho. 2021. ISSN 26754711. https://doi.org/10.46919/archv1n6-006.

MARGACA, Clara; RODRIGUES, Donizete. Espiritualidade e resiliência na adultez e velhice: uma revisão. Fractal: Revista de Psicologia. Niterói, no 02, v. 31, p.150- 
157, 2019. Disponível em http://www.scielo.br/scielo. Acessado em 7 de março. 2021. ISSN 1984-0292. https://doi.org/10.22409/1984-0292/v31i2/5690.

OLIVEIRA, Maria Clara Gonçalves Monteiro de; SALMAZO-SILVA, Henrique; GOMES, Lucy; MORAES, Clayton Franco; ALVES, Vicente Pauo. Elderly individuals in multigenerational households: Family composition, satisfaction with life and social involvement. Estudos de Psicologia. Campinas. v. 37, p.1-11, 2020. Disponível em http://www.scielo.br/scielo. Acessado em 1 de junho. 2021. ISSN 1982-0275. https://doi.org/10.1590/1982-0275202037e180081.

ORLANDO, Cássia; DIAS, João Carlos; BRASIL, Ricardo Taveiros; ARAÚJO, Tiago Coelho; BURITI, Marcelo de Almeida. Religiosidade na dimensão biopsicossocial do sujeito idoso. In: Universidade São Judas Tadeu - USJT. Artigo apresentado no XIV Simpósio Multidisciplinar da USJT realizado em 2008. São Paulo.

PANZINI, Raquel Gehrke; ROCHA, Neusa Sica da; BANDEIRA, Denise Ruschel; FLECK, Marcelo Pio de Almeida. Qualidade de Vida e Espiritualidade. Revista de Psiquiatria clínica. São Paulo. v. 34, n. 1, p.105-115, 2007. Disponível em http://www.scielo.br/scielo. Acessado em 28 de janeiro. 2021.

https://doi.org/10.1590/S0101-60832007000700014.

REINERS, Annelita Almeida Oliveira; AZEVEDO, Rosimeiry Capriata de Souza; CARDOSO, Joana Darc Chaves; ESPINOSA, Mariano Martinez; SANTANA, Aenne Zandonadi Rodrigues. Dissatisfaction with life and associated factors in older community-dwelling adults. Revista Brasileira de Geriatria e Gerontologia. Rio de Janeiro. v. 23, n. 6, p.1-9, 2020. Disponível em http://www.scielo.br/scielo. Acessado em 1 de junho. 2021. ISSN 1981-2256. https://doi.org/10.1590/198122562020023.190236 .

SIMKUNAS, J. B.; ANJOS, K. C. Namoro na velhice: UM estudo sobre os relacionamentos amorosos. In: Universidade São Judas Tadeu. Trabalho de conclusão de curso - Curso de Psicologia, Núcleo de Psicologia Organizacional - p. 66. São Paulo, 2001.

RC: 101667

Link de acesso: https://www. nucleodoconhecimento.com.br/psicologia/perspectivasde-qualidade 
TRENTINI, Clarissa Marceli; XAVIER, Flavio M. F.; FLECK, Marcelo Pio de Almeida. Qualidade de vida em idosos. In: PARENTE, M. A. M. P. Cognição e envelhecimento. Porto Alegre, Artmed (1ed), p. 19-20, 2006.

VELOZ, Maria Cristina Triguero; NASCIMENTO-SCHULZE, Clélia Maria; CAMARGO, Brigido Vizeu. Reflexões sociais do envelhecimento. Psicologia: Reflexão e Crítica. Porto Alegre, v. 12, № 12, p. 470-501, 1999. Disponível em http://www.scielo.br/scielo. Acessado em 21 de setembro. 2020. https://doi.org/10.1590/S0102-79721999000200015.

Enviado: Outubro, 2021.

Aprovado: Novembro, 2021. 